HIDEMICHI TANAKA

AKITA INTERNATIONAL UNIVERSITY, JAPAN

\title{
The Classicism of the Nara period (8th century) in Japan
}

Japanese Classicism of the Nara period

U NLIKE European ART History, where the development of styles has been a dominant consideration, the history of Japanese art has been approached against a schema of dynastic changes. It is fundamental that art history should be analyzed in terms of style itself, and not simply against the background provided by political history. We know that Eurocentrism has been criticized recently from a multiculturalist perspective, but this should be no obstacle to the use by other cultures of similar methods to those applied to European art history. Using such approaches, Japanese art could be seen to be compatible with Western art. My book, A History of Japanese Art, published in an English edition, is an attempt along those lines. ${ }^{\mathrm{I}}$

This paper is also one approach to explaining the Japanese style of Classicism, which could be compared with Renaissance Classical art in Europe. In the Nara period Japanese art was conceived in what we might call Classical terms through the observation of "noble simplicity" and "quiet grandeur", descriptions applied by Winckelmann to the classical style of ancient Greece. ${ }^{2}$ They can equally well be applied to the sculpture of the Nara period in works by Shogun Manpuku, Kuninaka Kimimaro, etc.

I. Hidemichi Tanaka, A History of Japanese Art, Joe Earle (trans.), Akita-city, Akita International University Press, 2008.

2. Johann Joachim Winckelmann, Geschichte der Kunst des Alterthums, Dresde, 1764 (History of Ancient Art has been translated into Japanese by Norio Nakayama, 2004). 
DOI: http://dx.doi.org/10.22201/iie.18703062e.2011.98.2367

238

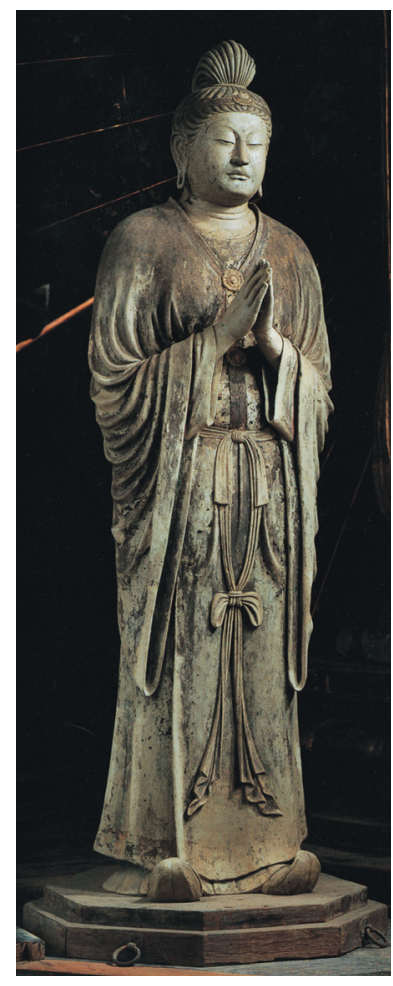

HIDEMICHI TANAKA
I. K. Kimimaro, Gakkō-Bosatsu, Todai-ji, Sangatsu-do, Nara.

While evidencing the planar style of which Wölfflin speaks, it also demonstrates the quality of absolute clarity and plasticity. ${ }^{3}$ Exemplars of this style include the sculptures of the Sangatsu-do of Todai-ji-particularly the pair of bodhisattvas Gakkō and Nikkō (figs. I, 2) - the Four Tennō of Kaidan-in (figs. 3, 4), and the Köfuku-ji sculptures of Eight Bushū (of which the Ashura is justly famous) and the Ten Daideshi. With their self-contained clarity and three-dimensional plasticity, they create a strictly limited ambient space. In the same way, we could compare the works from the Kamakura period, the era of bushi, or warriors, with the European Baroque period. Unkei, Tankei, Jokei etc. are remarkable sculptors in this style. ${ }^{4}$

3. Heinrich Wölfflin, Kunstgeschichtliche Grundbegriffe, Munich, Bruckmann (Principles of Art History), 1915 .

4. Hidemichi Tanaka, Unkei and the Great Masters of Japanese Baroque, Tokyo, Yudachisha, I998. 
2. K. Kimimaro, Nikkō-Bosatsu, Todai-ji,

Sangatsu-do, Nara.

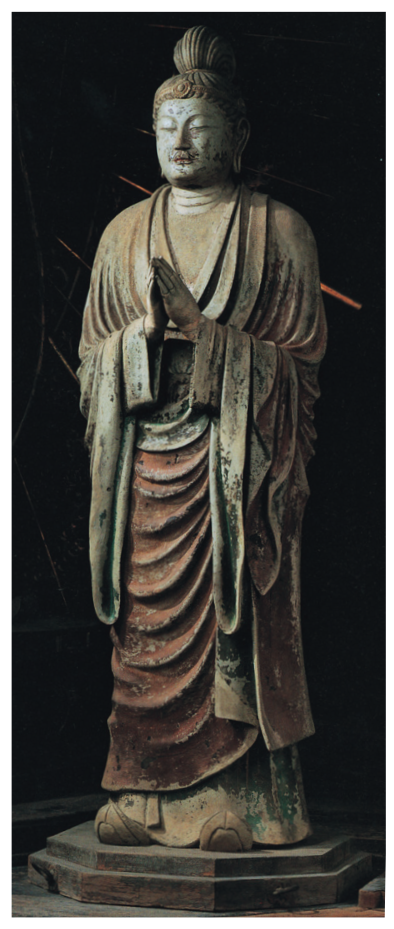

The images of Nikkō and Gakko bodhisattvas in the Sangatsu-do hall of the Todai-ji temple (figs. I, 2) share the distinctive eye shape. In my opinion these two images are among the very best examples of Tenpyo sculpture of the Classical period: the fullness of their faces, their aura of divinity, and the natural quality of their reverent poses elevate them above the merely human even while preserving a feeling of humanity. I would go a step further and suggest that these are idealized androgynous images, with the gentle hint of a smile suggesting a maternal quality. The preference for feminized bodhisattva images stems from the same emotional and spiritual impulses that underlie the popularity of images of the Virgin Mary in the West. It is an expression of people's need to incorporate the element of maternal love and compassion in their concept of divinity. The characteristically slanted eyes, with their gently bow-curved eyelids, enhance the realism of these feminine faces, and the firm mouth conveys a sense of living, human flesh. At the same time, when viewed directly from the front, these faces closely resemble those of the incised Shaka images on 
the lotus pedestal. In addition to the outline of the eyes, already discussed, the slightly narrow forehead, full face, and position of the mouth and nose are the same. Notwithstanding the rather mechanical outlines of the incised figures, one can well believe that these and the Gakko and Nikkō images are based on designs by the same artist. These two sculptures have been judged to be a pair and dubbed Nikkō and Gakkō (meaning "sunlight" and "moonlight") bodhisattvas because, while their robes are different, their faces and poses are almost identical. Scholars have posited that they were originally intended to represent a number of different deities, but none of their theories have been proved. More important is the obvious intent of the artists to produce not two identical figures (as evidenced by their different dress), but two distinct images with a very similar countenance. By actually creating two discrete images, the artist has given concrete expression to the duality of the bodhisattva, with its bisexual character. The rendering of these two images has a depth which allows us to consider this kind of interpretation; it is really beside the point whether Buddhist scripture corroborates the view. There are several subtle differences between the two. Nikkō has a painted moustache (perhaps added later), a more exposed chest area, and more sharply modelled drapery folds, all of which convey a more masculine impression, while Gakkō has a fuller neck and a belt draped decoratively below the waist, contributing to a more feminine appearance. These differences are also reflected, albeit very subtly, in the faces: the eyes and shape of the mouth make Nikkō appear more intellectual, while Gakkō seems slightly more emotional. It requires an extraordinary level of skill to produce two sculptures that are so similar but also express such subtle differences.

In Western art, a comparable expression of psychic duality can be found in Titian's Twin Venuses (Sacred and Profane Love, ca. I 5 16, Villa Borghese, Rome), and something similar also seems to be embodied in Leonardo's St. Anne with the Virgin Mary, the Infant Christ and St. John the Baptist (National Gallery, London). Philosophically speaking, the idea behind such images is distantly related to the previously mentioned theory of the origin of love, discussed in Plato- the idea that human beings were once two beings in one. The title of Nikkō and Gakkó bodhisattvas (apparently used only since the Edo period) is surprisingly appropriate for this pair of images, with its "two in one" implications, especially when one considers how sunlight and moonlight illuminate the light and dark halves of the world, which is one.

Many scholars have noted the stylistic similarities between the Nikkō and Gakkō bodhisattvas and the Four Tennō in the Kaidan-in (figs. 3, 4). Resem- 
3. K. Kimimaro, Kömokuten, Todai-ji, Kaidan-in, Nara.

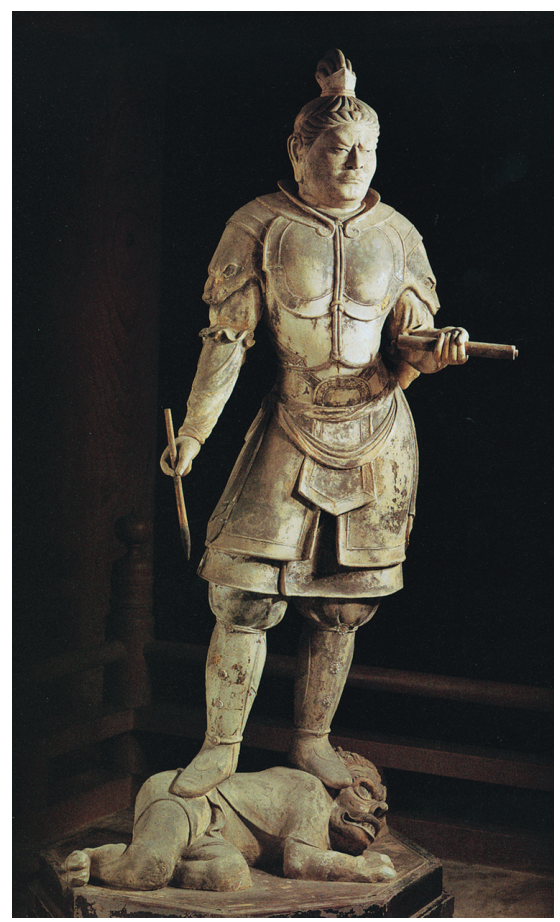

blances have been noted between the size of the figures, the composition of the clay, and the coloring technique, leading to the proposition that they might originally have been located in the same worship hall. In terms of artistic effect, the simultaneous expression of stillness and movement characteristic of both these masterful groups of figures binds them stylistically. To examine these similarities in greater detail, let us first focus on Kömokuten (fig. 3). The narrowed eyes of this image, gazing vigilantly into the distance under knitted brows, reveal the key characteristic we have noted in the two aforementioned images: the lines of both the upper and lower lids bow downward in the middle. Furthermore, both the modeling of the cheeks and the overall proportions of the face are nearly identical to those of Gakkō. Add to these similarities the narrow forehead and the rim of locks bordering it, the hair done up in a topknot, and the shape and size of the ears - all common to both images - and one cannot but conclude that a single artist was responsible for these sculptures. One can also confirm the likeness between the features of 


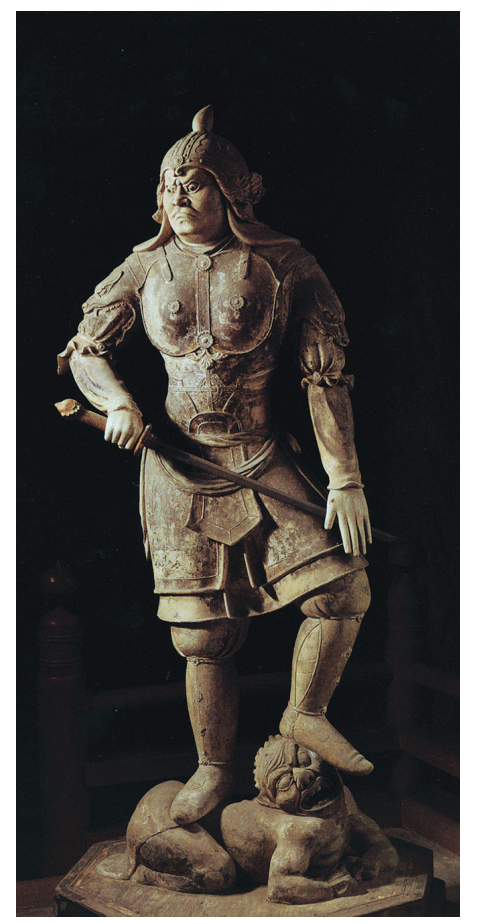

4. K. Kimimaro, Jigokuten, Todai-ji, Kaidan-in, Nara.

this Komokuten image and those of the incised images on the lotus-petal pedestal of the Daibutsu (fig. 5). Despite the contrasting expressions of serenity and anger, the eyes, the delineation of the base of the nose, and the outline of the lips are all similar, strongly suggesting that they follow the drawings of a single artist.

The Four Tennō display not only fierce expressions but also a powerful sense of movement despite being clad in armor. They have the short stature of Asians but are as vividly expressive as any ancient Greek or Renaissance Italian Classical sculpture. The helmeted Jigokuten (fig. 4), with down-turned mouth, glares out in a threatening manner as he stamps on a demon with his left foot. His grim face is a good example of realism in Eastern grotesquery. Zöchöten, standing with part of his weight resting on his spear, lets out a roar as he stamps on a demon's head with his right foot. The demon, despite his halfcrushed head, also maintains a defiant stare, indicating that he is not meekly accepting defeat. Kömokuten (fig. 3), on the other hand, holds a book and a 


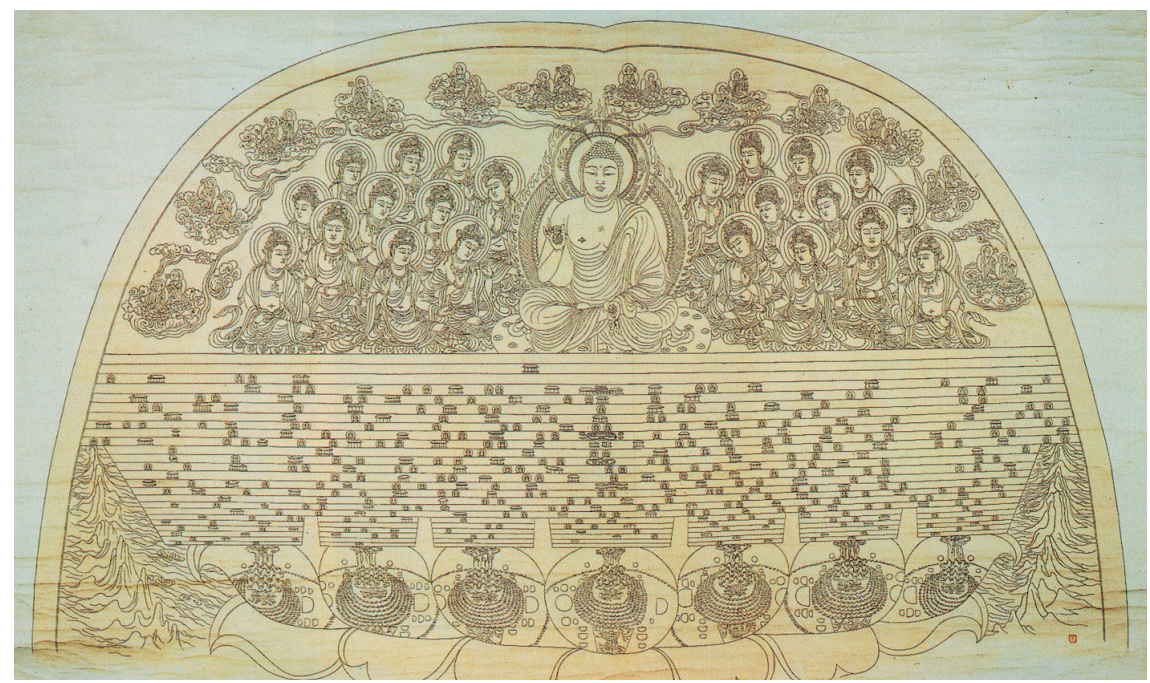

5. K. Kimimaro, engraving (schema) of the Lotus of the Daibutsu, Todai-ji, Kaidan-in, Nara.

scroll, symbols of scholarship. In Western art, such a figure would generally be portrayed as contemplative, but this Eastern image gazes outward with brows knit as if in anger. This is appropriate inasmuch as Eastern teachings concentrate on outward-looking, active morality rather than introverted contemplation. Tamonten is notable for the dynamic balance between the raised right arm, which holds a reliquary aloft, and the lowered left hand, which grips a spear. The demons on which all of the guardians stand have well-defined musculature.

It is also worth noting the differences between Nara style and Western classicism in the area of sculpture. Greek sculpture focused on the nude, emphasising the beauty of human proportions, and the sculptors of fifteenth and sixteenth-century Italy further elaborated the vocabulary developed by the Greeks to explore more complex expressions of human emotion. By contrast, Japanese Buddhist sculpture strives for the expression of a transcendental state beyond the human ego. A new self-awareness of Japan as a Buddhist state unified under a strong, legitimate government had taken root, especially under Emperor Shōmu, and this consciousness expresses itself in the Buddhist art of the period. 
Emperor Shōmu strongly favored Buddhism which, soon afterwards, was to become the state religion, and society itself was reorganized in accordance with a centralized Ritsuryō (Constitutional) system. In the Man'yōshü, "Collection of Ten Thousand Leaves" (poetry anthology), we can also appreciate the fundamental classical ideas and feelings of that period. ${ }^{5}$

\section{Daibutsu (Great Statue of Buddha) and its iconography}

We can be fairly sure that the Daibutsu of Nara, in all its monumentality, exuded a classic grandeur as well. Something of that majesty can be seen in the Fukūkenjaku Kannon in the Hokkedō of the Todai-ji, a work attributed to Kuninaka Kimimaro (d. 774). The Twelve Shinshō at Shin-yakushi-ji, while showing a somewhat greater degree of movement than the Four Tenno of the Kaidan-in, show the same basic formal characteristics. In the area of portraiture, the images of Ganjin and Gyōshin convey the same dignity in their austere portrayal of humanity. Here again, the mode of expression is characterized by a moderate and restrained idealism. ${ }^{6}$

The sixteen-meter cast-bronze figure of Rushana Butsu, consecrated in 752, may be described without exaggeration as a masterpiece that encapsulates the whole of East Asian Buddhist art, but both the Daibutsu and the other great sculptures of the time are manifestations of more than just Buddhist culture. In the same way that Buddhist philosophy finds very little direct expression in the verses of the Man'yoshiu, the sculpture of eighth-century Nara communicates above all a sense of humanity that transcends religious faith, showing just how strong the links are that unite the traditions of human representation running from Greece to Gandhara to China to Japan. Concerning the iconography of the Rushana Butsu, it is the Kegon sect's cosmology that is important. It is interesting that there are some similarities between the Kegon account of the process of enlightenment (a scheme which can be mapped onto Kegon cosmography) and Ficino's Neo-Platonist metaphysics.

5. Hidemichi Tanaka, Tenpyo "Classicism" and that Age, Kyoto, Minerva-Shobo, 20 I I (forthcoming).

6. Hidemichi Tanaka, Michelangelo of Tenpyo period, Tokyo, Yudachisha, I996. As we have already seen, this sense of continuity was not just a matter of copying what had been done before but resulted from the sculptors' success in honing their own distinctive styles to a level that aspired to the highest achievements of world sculpture. 
According to Kegon teaching, the universe can be understood as comprising four different levels or stages of enlightenment, the jihokkai or material world, the rihokkai or ideal world, the riji muge hokkai or material and physical world of absolute attachment and freedom from obstacles, and finally the jiji muge hokkai or physical world of absolute non-attachment and freedom from obstacles. As the name suggests, the first of these represents the ordinary world of everyday experience, while the second, the world of the intellect or spirit, the third, the stage at which the believer attains an appreciation of the inseparability of the physical and the material, and the fourth, the final stage of enlightenment when the believer at last comes to understand the unique, immutable kernel of his own being and its links with the rest of the universe. This is not unlike the Neo-Platonist metaphysical fivefold (occasionally sixfold) scheme of emanation: the One, Mind, Soul, Cosmos, and Matter. In reverse order to the Kegon account, Ficino's standard scheme, which broadly follows the second-century AD philosopher Plotinus, comprises the One, which is ineffable and an absolute singularity; Mind, which is the realm of the timeless creative causes; Soul, which is the principle of motion and introduces a greater degree of plurality than Mind; Body (including the World Soul's Body, i.e. the Cosmos); and Matter, which is pure potentiality, existing solely in combination with Soul. Of course one should not push the analogy with Kegon philosophy too far, but there are some similarities between the "absolute singularity" of the One and the "physical world of absolute non-attachment and freedom from obstacles," the latter representing the stage of enlightenment where the believer first becomes aware of the existence of Indra (Vairocana), located at the epicentre of a vast, infinite net of cosmic relationships. ${ }^{7}$

Even if the Kegon world view is essentially non-hierarchical, the scene engraved on the petals of the Daibutsu's dais, whose iconography is drawn from the Bonmôkyô [Sutra of Indra's net] (fig. 5), is divided into three distinct bands: upper, middle and lower. The upper band is depicted as the realm of Buddhas, with Shaka, the historical Buddha, at its centre, eleven bodhisattvas ranged around him to left and right, and several other Buddhas in the midst of the brilliant light that rises from Shaka's head. In all, the upper band includes fifty-seven sacred beings. The middle band depicts the illusory world of living beings, including humans, and is subdivided into three smaller zones representing, from top downwards, the mushikikai or realm of detachment from all 
physical ties, the intermediate shikikai whose occupants are freed from the appetite for sex and food but still subject to physical ties, and the lower yokukai whose occupants remained enslaved by the craving for food and sex. All the living things in the universe are shown crossing and recrossing the boundary between life and death within the twenty-five horizontal lines drawn across this realm, four of them defining the mushikikai, seven the shikikai and fourteen the yokukai. The Japanese are depicted along with the inhabitants of India and China above the eighth line from the bottom, but some of them are falling into the lower worlds of hell, wild beasts, or hungry ghosts. ${ }^{8}$

The lowest of the three major bands is divided into seven circular areas, each of them enclosing a depiction of the whole world arranged around Mount Sumeru, a mighty peak traditionally said to rise 160,000 yujun (in Sanskrit, yojana is equivalent to as much as nine and a half miles) from the seabed, or about 760,000 miles below and a similar distance above sea level, while the ocean around its base is surrounded by seven ranges of golden mountains. Japan, China and India are represented as a series of islands floating in another ocean that lies beyond these mountain ranges, while the sun, moon and other celestial bodies revolve around the middle slopes of Mount Sumeru. It could be argued that this arrangement accords with Ficino's conception of the universe in as much as the uppermost band is occupied by Buddhas, corresponding with his domain of the "One," while his intermediate "Soul" and "Cosmos" correspond with the tripartite central band of the Daibutsu dais engravings, and "Matter" corresponds with the lowest band. Even though Buddhism is a polytheistic faith, its conception of the universe, with supernatural beings occupying a higher-order realm and our own world assigned to a physical, lower-order realm, is not so very different from Ficino's monotheistic cosmology. This very specific mental organization of the universe formed the basis for all Tenpyo period artistic visualizations of the cosmos, and it would be no exaggeration to suggest that in both in eighth-century Nara and fifteenth-century Florence the existence of such comprehensive systems was a contributory factor in the emergence of major works of art that sought to embrace every aspect of human experience. In painting, alas, there is very little remaining from this period. The great wall paintings in the Kondō at Horyu-ji were all but destroyed by fire in 1949, though photographs of the paintings

8. Encho Tamura, The State and the Buddhism on the Ancient Japan. The Studies of the Foundation of Todai-ji Temple, Tokyo, Yoshikawa-Kobun-Kan, I999. 

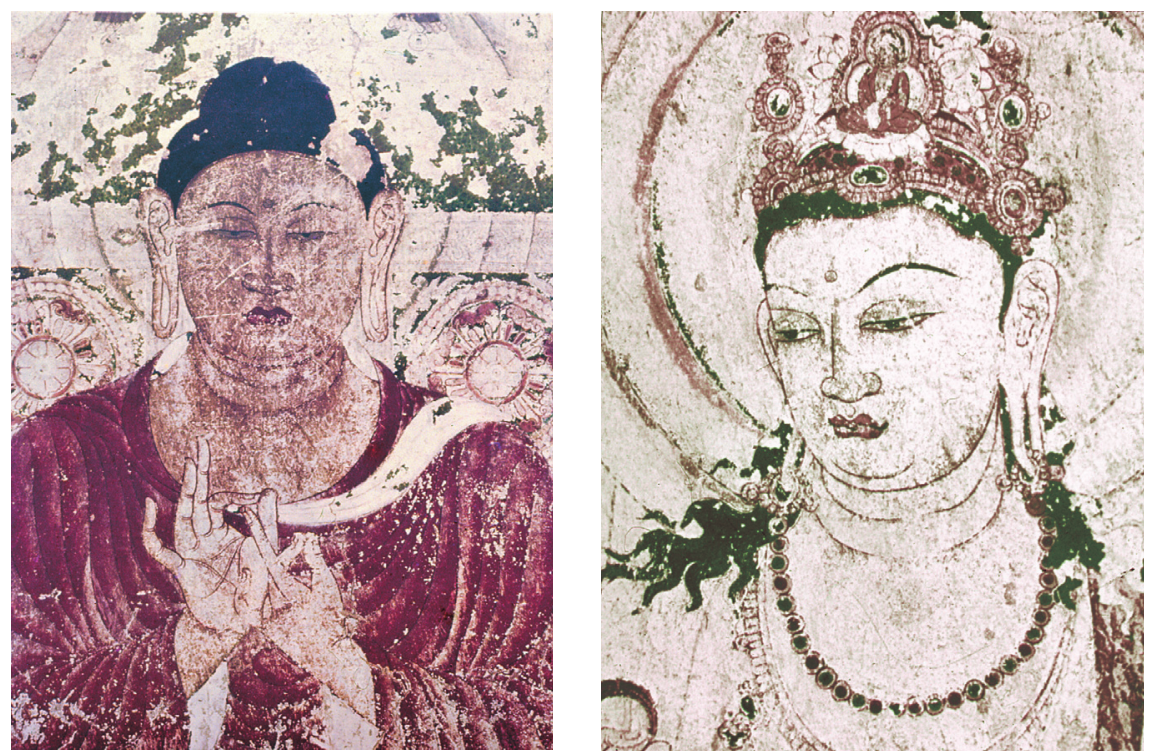

6. Amida Paradise (details), Wall 6, Horyu-ji Kondo, Nara.

taken before they were damaged show what a precious cultural asset was lost to the world. The paintings portrayed three Buddhas-Shaka, Amida (fig. 6), and Yakushi-each in its own paradise. While the same type of outline is used for each of the images, the brushwork differs subtly. Although linear and planar in approach, they are by no means lacking in a sense of three-dimensional plasticity. The faces of the twelve disciples of Shaka portrayed in the mural each express intelligence and integrity. Although the basic technique seen here can be thought of as an import from Tang China, these paintings in their entirety are imbued with a unique sense of vitality that places them squarely in the Japanese artistic tradition.

The international character of Nara culture is underlined by the fact that many of its leading practitioners were of foreign birth or origin, a sign of the spirit of openness that is perhaps best expressed by the city's lack of defensive walls: Nara was surrounded only by nature.

The population of eighth-century Nara is thought to have been somewhere between 70,000 and 200,000 . It was laid out on a roughly square plan extending 4.2 kilometres from east to west and 4.7 kilometres from north 
DOI: http://dx.doi.org/10.22201/iie.18703062e.2011.98.2367

\section{8}

HIDEMICHI TANAKA

to south. Suzaku Avenue ran through the centre of the city, with the magnificent buildings of the Imperial palace at its northern extremity. Ancient Nara is normally said to have been modelled on the Tang capital at Chang'an (present-day Xi'an) but it would be truer to say that rather than being a direct copy its plan reflected experience gained during the construction of the earlier Japanese capital at Fujiwarakyō. The palace was the center of political activity, while religious life was based around the great temples in the east of the city: the Todai-ji, the Kōfukuji, the Gangōji and others. ${ }^{9}$ 's

9. Tanaka, Michelangelo of Tenpyo period. 